\title{
Change in Practice of Radioactive lodine Administration in Differentiated Thyroid Cancer: A Single-Centre Experience
}

\author{
Ayanthi Wijewardene ${ }^{a, b} \quad$ Matti Gild ${ }^{a, b} \quad$ Carolina Nylén ${ }^{c}$ Geoffrey Schembrib, d \\ Paul Roach ${ }^{b, d}$ Jeremy Hoang ${ }^{\text {b,d }}$ Ahmad Aniss $^{c}$ Anthony Glover ${ }^{b, c}$ \\ Mark Sywak $^{b, c}$ Stan Sidhu ${ }^{\text {b, c }}$ Diana Learoyd ${ }^{b}$ Bruce Robinson $^{a, b}$ \\ Lyndal Tacon $^{\mathrm{a}, \mathrm{b}}$ Roderick Clifton-Bligh ${ }^{\mathrm{a}, \mathrm{b}}$
}

${ }^{a}$ Department of Endocrinology, Royal North Shore Hospital, Sydney, NSW, Australia; b ${ }^{b}$ aculty of Medicine, University of Sydney, Sydney, NSW, Australia; 'Endocrine Surgery Department, Royal North Shore Hospital, Sydney, NSW,

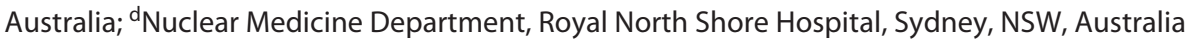

\section{Keywords}

Thyroid cancer · Radioactive iodine - Adjuvant therapy · ATA risk stratification

\begin{abstract}
Objective: Our study aimed to analyse temporal trends in radioactive iodine (RAI) treatment for thyroid cancer over the past decade; to analyse key factors associated with clinical decisions in RAI dosing; and to confirm lower activities of RAl for low-risk patients were not associated with an increased risk of recurrence. Methods: Retrospective analysis of 1,323 patients who received RAl at a quaternary centre in Australia between 2008 and 2018 was performed. Prospectively collected data included age, gender, histology, and American Joint Committee on Cancer stage (7th ed). American Thyroid Association risk was calculated retrospectively. Results: The median activities of RAI administered to lowrisk patients decreased from $3.85 \mathrm{GBq}(104 \mathrm{mCi})$ in 20082016 to $2.0 \mathrm{GBq}(54 \mathrm{mCi}$ ) in 2017-2018. The principal driver of this change was an increased use of $1 \mathrm{GBq}(27 \mathrm{mCi})$ from $1.3 \%$ of prescriptions in $2008-2011$ to $18.5 \%$ in $2017-2018$. In patients assigned as low risk per ATA stratification, lower
\end{abstract}

karger@karger.com www.karger.com/etj Karger\% activities of $1 \mathrm{GBq}$ or $2 \mathrm{GBq}$ ( $27 \mathrm{mCi}$ or $54 \mathrm{mCi}$ ) were not associated with an increased risk of recurrence. In patients assigned to intermediate- or high-risk categories who received RAl as adjuvant therapy, there was no difference in risk of recurrence between $4 \mathrm{GBq}(108 \mathrm{mCi})$ and $6 \mathrm{GBq}(162 \mathrm{mCi})$. Conclusions: Our data demonstrate an evolution of RAI activities consistent with translation of ATA guidelines into clinical practice. Use of lower RAI activities was not associated with an increase in recurrence in low-risk thyroid cancer patients. Our data also suggest lower RAI activities may be as efficacious for adjuvant therapy in intermediate- and high-risk patients.

(c) 2021 European Thyroid Association Published by S. Karger AG, Basel

\section{Introduction}

The incidence of thyroid cancer is increasing worldwide [1]. In Australia, thyroid cancer is increasing more than any other malignancy, with incidence rising from 2.7 to 13 per 100,000 persons between 1982 and 2019 [2, $3]$. Over $97 \%$ of thyroid cancer is well-differentiated, originating from thyroid follicular cells. Differentiated
Correspondence to:

Ayanthi Wijewardene, awij1156@uni.sydney.edu.au 
thyroid cancer includes papillary, follicular, or Hurthlecell neoplasms [4]. Radioactive iodine (RAI) is considered following total thyroidectomy for differentiated thyroid cancer for 3 reasons: to ablate remnant thyroid tissue in low-risk patients; prevent recurrent disease in highrisk patients (adjuvant therapy); or to treat residual or metastatic disease [5].

Clinical paradigms have shifted over the past decade towards the use of lower RAI activities. The HiLo and ESTIMABL1 studies showed no difference in biochemical or structural recurrence following $1.1 \mathrm{GBq}(29.7 \mathrm{mCi})$ or 3.7 $\mathrm{GBq}(100 \mathrm{mCi})$ for low-risk patients treated with ablative intent in the short term or 5 year follow data [6-9]. In 2015, the American Thyroid Association (ATA guidelines) supported the use of lower activities of RAI therapy by recommending lower activities for low- and intermediate-risk categories [5]. It is well established that patients with metastatic disease have improved survival outcomes with RAI treatment with up to $7.4 \mathrm{GBq}(200 \mathrm{mCi})$ [10, 11]. Conversely, higher RAI activities are associated with increased risks including sialadenitis and secondary malignancy [12].

Adjuvant therapy is defined as treatment of suspected but not confirmed residual disease [13]. Proposed indications for adjuvant therapy include gross extra-thyroidal extension (ETE), lymph node involvement $>3 \mathrm{~cm}$ and, for follicular thyroid cancers, $>4$ foci of vascular invasion [14-16]. The ATA guidelines define low- and high-risk categories based on absence or presence of these features, respectively, and also include an intermediate risk group defined by minimal extra-thyroidal extension, and/or venous invasion, and/or lymph node involvement $<3 \mathrm{~cm}$, and/or $>5$ involved lymph nodes [5]. In addition, tumour size $>4 \mathrm{~cm}$ and/or post-operative thyroglobulin $(\mathrm{Tg})>10$ $\mathrm{ng} / \mathrm{L}$ may be associated with increased risk of recurrence, although neither feature has yet been included in ATA guidelines for baseline risk assessment [17-19]. The appropriate RAI activities for adjuvant therapy remains unclear, with activities up to $5.5 \mathrm{GBq}(150 \mathrm{mCi})$ recommended [5]. A paucity of prospective trials and ambiguous definitions of adjuvant therapy haveled to inconsistent dosing decisions based on clinical discretion rather than evidence [13].

Our primary aim was to analyse the temporal trends in RAI treatment for thyroid cancer at our institution over the past decade. Our secondary aims were to analyse key factors associated with clinical decisions in RAI dosing; and to confirm lower activities of RAI for low-risk patients were not associated with an increased risk of recurrence. We hypothesized our clinical practice of RAI ad- ministration had incrementally changed to favour use of lower activities in line with a global shift in clinical paradigms. We also wished to specifically examine whether different RAI choices made by independent clinicians had affected recurrence risk when used in the adjuvant (rather than ablative) setting.

\section{Methodology}

All patients aged $>18$ years who underwent a total or completion thyroidectomy followed by RAI between 2008 and 2018 for differentiated thyroid cancer were identified using the thyroid cancer database at Royal North Shore Hospital, the largest volume thyroid surgery unit in Australia. Three (3) surgeons performed over $85 \%$ of all thyroid cancer surgery registered in the database. One hundred and thirty (130) clinicians prescribed RAI over the time period, with 6 clinicians prescribing over $75 \%$ of all RAI activity. Our institution had no formal guidelines for the choice of RAI activity in this time frame and dosing decisions were left to the discretion of the clinician prescribing RAI and reviewed by the nuclear medicine specialist. Some clinicians, however, did have the opportunity to present at a fortnightly multidisciplinary team meeting attended by endocrinologists, nuclear medicine physicians, surgeons, pathologists, and radiologists, to aid activity selection. Clinical characteristics extracted included: therapeutic activities, age, gender, histology, tumour size, stimulated Tg, lymph node status, vascular invasion, ETE, presence of metastases and the American Joint Committee on Cancer stage (AJCC 7th ed, 7th ed.; defined by pathological tumour size [pT1-4], central [N1a], and lateral [N1b] lymph node involvement and presence of metastasis [M1]). In addition to these features, ATA thyroid cancer risk categories were retrospectively assigned for each patient (by A.W.) as defined in online supplementary Table 1 (for all online suppl. material, see www.karger.com/doi/10.1159/000516358). Patients with anaplastic, insular, poorly differentiated, and medullary thyroid cancer were excluded, along with lymphoma of the thyroid gland. RAI activities were categorized into 3 groups: low $(<1.3$ $\mathrm{GBq}, 35 \mathrm{mCi})$, intermediate (1.3-3.74 GBq; 35-101 $\mathrm{mCi})$, and high ( $\geq 3.75 \mathrm{GBq} ; 101 \mathrm{mci})$. The high-activity group was further divided into $\mathrm{H} 1$ (3.75-5.39 Gbq; $101-145.7 \mathrm{mCi})$ and $\mathrm{H}_{2}(\geq 5.4 \mathrm{GBq} ; \geq 145.7$ $\mathrm{mCi})$. Recurrence was defined as either surgical intervention or administration of a second activity of RAI. We attempted to examine recurrence as distinct from persistent disease by 2 additional steps: (1) we excluded patients with uptake only in the thyroid bed; (2) we also excluded patients with distant metastasis on baseline imaging or on initial post-treatment iodine uptake scan, as they were frequently administered an additional activities of RAI for persistent disease (Fig. 1). Progression-free survival was defined as the time to recurrence and was censored to death or end of study period. Survival data were obtained from medical records or the Ryerson Index, which is an index to death notices and obituaries appearing in Australian newspapers [20]. Adjuvant therapy was defined when RAI was given for suspected but not confirmed residual disease as per the above criteria. These included intermediate-risk patients with a tumour size $>4 \mathrm{~cm}$, microscopic ETE, central (N1a), and lateral (N1b) lymph node involvement or postoperative thyroid-stimulating hormone stimulated Tg between 10 
Fig. 1. Study design.

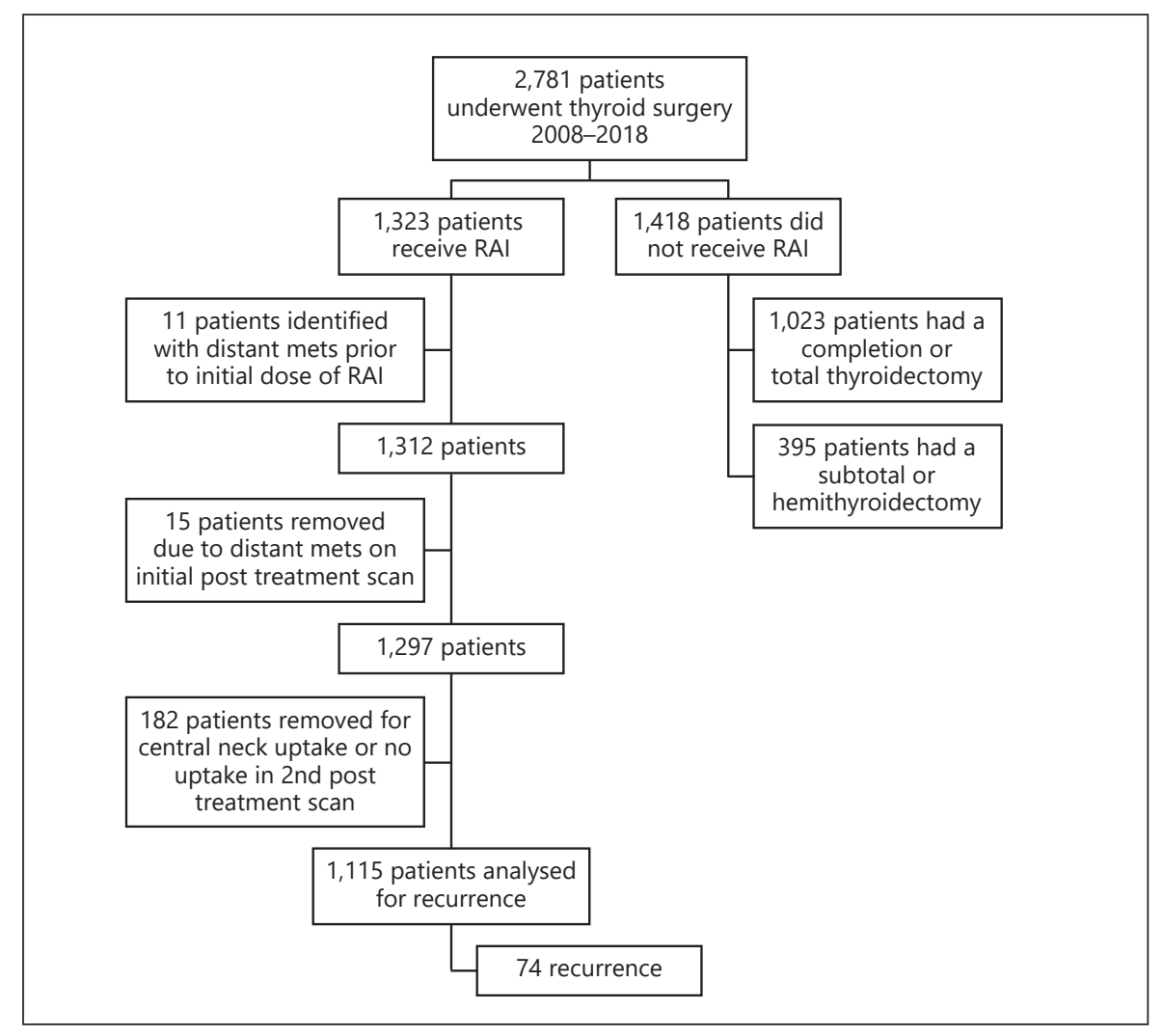

and $30 \mu \mathrm{g} / \mathrm{L}$; and high-risk patients without structural disease and post-operative thyroid-stimulating hormone stimulated $\mathrm{Tg}<30$ $\mu \mathrm{g} / \mathrm{L}$. The study was approved by the Human Research Ethics Committee at Northern Sydney Local Health District (ETH00360/ STE006443).

\section{Statistical Analysis}

Descriptive statistics were presented as mean ( \pm standard deviation) for normally distributed data; median (interquartile range, [IQR]) for continuous non-normally distributed variables; and frequencies and proportions for categorical variables. Oneway ANOVA compared means between the 3 activities groups. Mann-Whitney tests were used to compare medians between 2 groups. $\chi^{2}$ test was used to compare categorical groups, including histology, gender, ATA risk, and AJCC staging. Linear regression was used to assess changes in RAI activities over time. Univariate and multivariate binomial regression analysis was used to elicit factors associated with dose categories. A multivariate binomial regression analysis of RAI activities categories included gender, age, histology, pathological staging, venous invasion, ETE, and lymph node involvement; distant metastasis was not included in this analysis. Kaplan-Meier curves analyzed progression-free survival (PFS), defined as time to recurrence. A $p$ value of $\leq 0.05$ was considered statistically significant. Statistical analyses were conducted using Statistical Package for Social Sciences version 26 (SPSS Inc., Chicago, IL, USA). Figures were created using GraphPad Prism version 8.0.0 for Windows (GraphPad Software, San Diego, CA, USA).

\section{Results}

\section{Patient Characteristics}

One thousand two hundred and twenty-three $(1,323)$ patients received RAI between 2008 and 2018. One hundred and twenty (120) patients were administered a low activity, 259 received an intermediate activity and 944 received high activities. The median follow-up was 42 months (IQR 15.0-81.3 months). The characteristics of the patients are outlined in Table 1. Between 2008 and 2018, 1,418 patients did not receive RAI following thyroid cancer surgery. Of these patients, 1,023 patients had a total or completion thyroidectomy and 395 underwent a hemi or subtotal thyroidectomy (online suppl. Table 2). The odds of not receiving RAI was 1.2 times more likely in 2017-2018 than 2008$2010(p=0.02)$; with the increase in non-RAI treatment driven by an increase in subtotal or hemithyroidectomy over a total thyroidectomy (OR 2.63, 1.86-3.69, $p<0.001$ ).

\section{RAI Activities Have Decreased over the Past Decade}

Linear regression demonstrated mean RAI activities decreased by $0.135 \mathrm{GBq}(3.6 \mathrm{mCi})$ each year from 2008 $(p<0.001)$. Administered RAI activity was analyzed across 3 retrospective time intervals: $2008-2010,2011-$ 
Table 1. Baseline characteristics of patients administered an initial dose of radioactive 2008-2018

\begin{tabular}{|c|c|c|c|c|}
\hline & $\begin{array}{l}\text { Low dose, } \\
n=120\end{array}$ & $\begin{array}{l}\text { Intermediate dose, } \\
n=259\end{array}$ & $\begin{array}{l}\text { High dose, } \\
n=944\end{array}$ & $p$ value \\
\hline Dose GBq (median, IQR) & $1.03(1-1.08)$ & $2.07(2.0-2.58)$ & $4.14(4.0-4.4)$ & \\
\hline Age $($ mean $\pm S D)$ & $47.27( \pm 12.39)$ & $48.47( \pm 13.61)$ & $51.29( \pm 15.56)$ & 0.002 \\
\hline Male, $n(\%)$ & $20(16.67)$ & $54(20.8)$ & $270(28.6)$ & 0.002 \\
\hline \multicolumn{5}{|l|}{ Histology, $n(\%)$} \\
\hline Papillary thyroid cancer & $43(35.8)$ & $75(30)$ & $332(35.2)$ & 0.05 \\
\hline Multifocal papillary thyroid cancer & $44(36.7)$ & $128(49.4)$ & $415(44)$ & \\
\hline Follicular variant thyroid cancer & $15(12.5)$ & $25(9.7)$ & $63(6.7)$ & \\
\hline FTC & $9(7.5)$ & $23(8.9)$ & $81(8.6)$ & \\
\hline Hurthle-cell cancer & $9(7.5)$ & $8(8.9)$ & $53(5.6)$ & \\
\hline \multicolumn{5}{|l|}{ Staging (AJCC), $n(\%)$} \\
\hline $1, n=679$ & $85(70.8)$ & $174(67.2)$ & $420(44.5)$ & $<0.001$ \\
\hline $2, n=132$ & $11(9.2)$ & $33(12.7)$ & $88(9.3)$ & \\
\hline $3, n=343$ & $20(16.7)$ & $44(17)$ & $279(29.6)$ & \\
\hline $4 \mathrm{~A}, n=156$ & $4(3.3)$ & $4(1.5)$ & $147(15.6)$ & \\
\hline $4 \mathrm{C}, n=7$ & & $1(0.4)$ & $6(0.6)$ & \\
\hline NA & & $2(0.8)$ & $4(0.4)$ & \\
\hline \multicolumn{5}{|l|}{ ATA risk, $n(\%)$} \\
\hline Low, $n=290$ & $50(41.6)$ & $98(37.8)$ & $142(15)$ & $<0.001$ \\
\hline Intermediate, $n=774$ & $58(48.3)$ & $129(49.8)$ & $587(62.1)$ & \\
\hline High, $n=182$ & $6(5)$ & $13(3.8)$ & $163(17.2)$ & \\
\hline NA & $6(5)$ & $19(7.3)$ & $52(5.5)$ & \\
\hline
\end{tabular}

FTC, follicular thyroid cancer; ATA, American Thyroid Association; IQR, interquartile range.

2016, and 2017-2018. As shown in Figure 2, the number of high activities decreased from $89 \%(269 / 302)$ of all activities administered in 2008-2010 to $61 \%(159 / 259)$ of doses in 2017-2018. The number of low activities increased from $1.3 \%$ of all activities (4/302) in 2008-2010 to $18.5 \%(48 / 259)$ in $2017-2018$. The odds of receiving a low activity compared to a high activity were 24 times more likely in 2017-2018 than 2008-2010 ( $p<0.001)$.

Data for 1,246 patients were available to permit retrospective stratification of risk according to the modified ATA guidelines: 290 patients were stratified as low risk, 774 as intermediate risk, and 182 as high risk. Of patients stratified as low risk from 2008 to $2018,17.2 \%$ received a low activity, while $49.0 \%$ received a high activity. Lowrisk patients had a OR of 33.2 (CI 14.8-69.6) to be administered $1 \mathrm{GBq}$ over a higher activity in 2017-2018 $(p<$ $0.001)$. In contrast, intermediate-risk patients had a OR of 0.38 (CI $0.27-0.55, p<0.001$ ) of being administered $\geq 4$ GBq activity. There was no statistical difference in the administration of $\geq 4 \mathrm{GBq}$ activity between 2017 and 2018 compared to 2008-2016 for high-risk patients $(p=0.24)$.

\section{Factors Associated with Activity Choice}

A multivariate analysis was performed to determine factors associated with activity selection in 214 patients

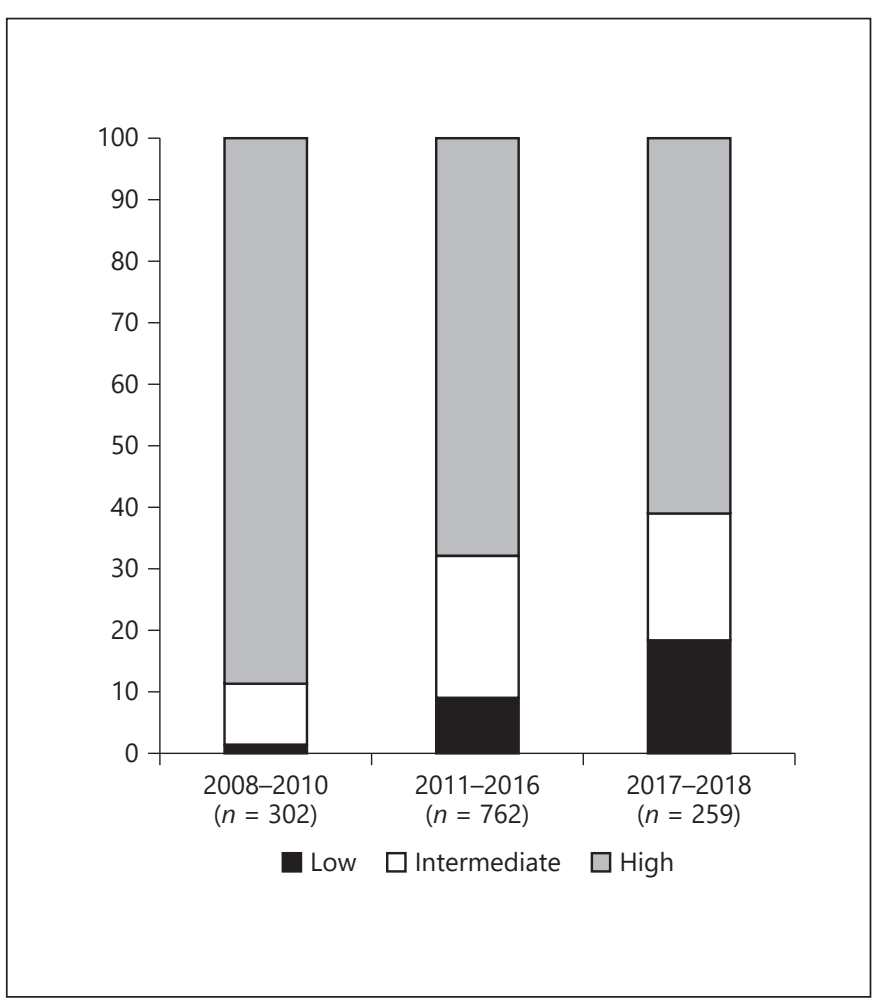

Fig. 2. Initial RAI dose over 3 time points, 2008-2010, 2011-2016, and 2017-2018. RAI, radioactive iodine. 
Table 2. Factors associated with a low and high dose in 2017-2018

\begin{tabular}{|c|c|c|c|c|}
\hline & \multicolumn{2}{|c|}{ Univariate Analysis } & \multicolumn{2}{|c|}{ Multivariate Analysis } \\
\hline & $p$ value & OR (95\% CI) & $p$ value & OR (95\% CI) \\
\hline \multicolumn{5}{|l|}{ Low dose, $n=259$} \\
\hline Female, $n=152$ & 0.21 & $1.62(0.76-3.45)$ & 0.446 & $1.43(0.57-3.61)$ \\
\hline Age (by 10 years) & 0.15 & $0.86(0.70-1.06)$ & 0.028 & $0.73(0.55-0.97)$ \\
\hline $\mathrm{Tg}$ & 0.49 & $0.99(0.99-1.01)$ & 0.865 & $1.00(0.998-1.00)$ \\
\hline No venous invasion & 0.002 & $2.85(1.45-5.63)$ & 0.016 & $2.72(1.20-6.14)$ \\
\hline \multicolumn{5}{|l|}{ Lymph node (ref: N1b) } \\
\hline N0, $n=93$ & 0.008 & $3.99(1.44-11.10)$ & 0.003 & $7.31(1.94-27.48)$ \\
\hline N1a, $n=72$ & 0.16 & $2.19(0.73-6.53)$ & 0.136 & $2.625(0.739-9.33)$ \\
\hline \multicolumn{5}{|l|}{ Tumour size (ref: pT3) } \\
\hline pT $1, n=78$ & $<0.001$ & $4.53(2.01-10.28)$ & 0.000 & $7.527(2.465-22.982)$ \\
\hline $\mathrm{pT} 2, n=52$ & 0.13 & $2.08(0.81-5.35)$ & 0.165 & $2.283(0.712-7.317)$ \\
\hline No ETE, $n=98$ & 0.02 & $2.20(1.16-4.20)$ & 0.928 & $0.961(0.407-2.268)$ \\
\hline \multicolumn{5}{|l|}{ High dose, $\mathrm{n}=214$} \\
\hline Male, $n=62$ & 0.018 & $2.04(1.13-3.70)$ & 0.024 & $2.45(1.12-5.34)$ \\
\hline Age (by 10 years) & 0.16 & $1.12(0.96-1.31)$ & 0.007 & $1.40(1.10-1.78)$ \\
\hline $\operatorname{Tg}$ & 0.191 & $1.01(0.99-1.02)$ & 0.771 & $1.00(0.99-1.01)$ \\
\hline Venous Invasion, $n=105$ & $<0.001$ & $2.52(1.50-4.21)$ & 0.016 & $2.32(1.17-4.61$ \\
\hline \multicolumn{5}{|l|}{ Lymph nodes (ref: N0) } \\
\hline $\mathrm{N} 1 \mathrm{a}, n=72$ & 0.008 & $2.33(1.25-4.34)$ & 0.001 & $3.96(1.71-9.14)$ \\
\hline $\mathrm{N} 1 \mathrm{~b}, n=49$ & $<0.001$ & $5.17(2.39-11.17)$ & 0.000 & $22.81(6.67-78.05)$ \\
\hline \multicolumn{5}{|l|}{ Tumour size (ref: pT1) } \\
\hline $\mathrm{pT} 2, n=52$ & 0.168 & $1.57(0.83-2.99)$ & 0.013 & $3.35(1.28-8.72)$ \\
\hline pT3, $n=84$ & $<0.001$ & $3.22(1.76-5.91)$ & 0.001 & $4.61(1.89-11.26)$ \\
\hline ETE, $n=116$ & $<0.001$ & $2.51(1.50-4.19)$ & 0.644 & $1.20(0.56-2.53)$ \\
\hline
\end{tabular}

ETE, extra-thyroidal extension; Tg, thyroglobulin.

treated in most recent years (2017-2018). Thirty (30) of the patients were low-ATA risk, 143 intermediate risk, 31 high risk and 10 were unable to be allocated into an ATA category. As shown in Table 2 factors associated with lower activities included younger age, $\mathrm{pT} 1$, absence of venous invasion and absence of lymph node involvement, while factors associated with high activities were male gender, increasing age, pT2, pT3, N1a, and N1b disease.

\section{Recurrence}

Seventy-four (74) patients had a recurrence when patients treated for thyroid bed uptake and distant metastasis were excluded from analysis. Median time to recurrence was 14 months (IQR 10-31 months).

In the 1,115 patients included in the recurrence analysis, the initial RAI activities were administered in 20082010 for 236 patients, $2011-2016$ for 630 patients and 2017-2018 for 249 patients. Of patients who had recurrence, 18 had an initial treatment in 2008-2010, 52 in 2011-2016, and 4 in 2017-2018. Recurrence was 5.06 (CI 1.73-13.96) times more likely to have occurred in patients who received an initial activities in 2008-2010 than pa- tients treated in 2017-2018 $(p=0.002)$. Similarly, patients who received RAI in 2011-2016 were 5.5 (CI 2.04-14.41) times more likely to have recurred than those whose initial dose was in 2017-2018 $(p<0.001)$.

Analysis of these patients by baseline ATA risk showed recurrence in $3.4 \%$ of low-risk patients, 3.7\% of intermediate-risk and $16.5 \%$ of high-risk patients. There was no statistical difference in the risk of recurrence between the 4 different activity categories (low, intermediate, $\mathrm{H} 1$ and $\mathrm{H} 2)$ in low-risk patients $(p=0.16)$. In intermediate- and high-risk patients, there was no difference in recurrence risk between $\mathrm{H} 1$ and $\mathrm{H} 2$ activities; $p=0.07$ and $p=0.56$, respectively.

\section{Progression-Free Survival}

ATA low- and intermediate-risk patients had longer PFS than high-risk patients $(p<0.001)$, but there was no difference in PFS between low- and intermediate-risk patients $(p=0.58)$. No statistically significant difference in PFS was seen between $\mathrm{H} 1$ and $\mathrm{H} 2$ activities categories for either the intermediate $(p=0.11)$ or high-risk patients $(p=0.38)$. 


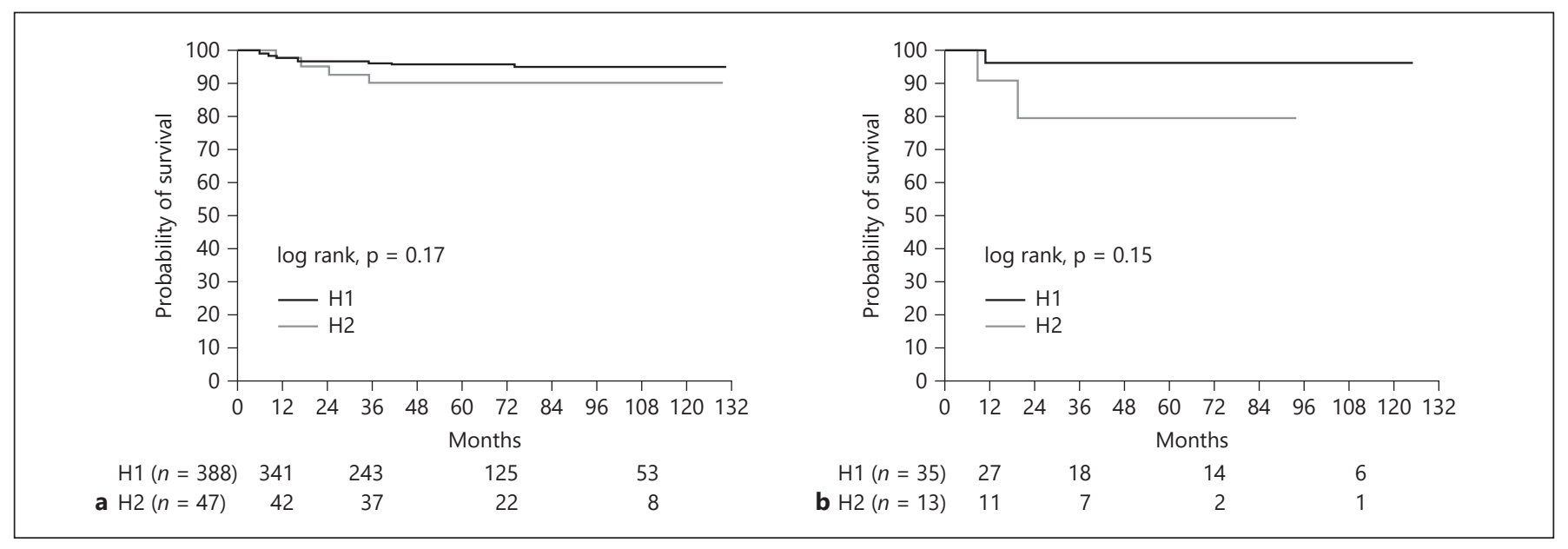

Fig. 3. PFS using Kaplan-Meir Curve in patients treated with adjuvant therapy in H1 (3.75-5.39 Gbq; 101-145.7 $\mathrm{mCi})$ and $\mathrm{H} 2(\geq 5.4 \mathrm{GBq} ;>145.7 \mathrm{mCi})$ treated patients in intermediate risk (a) and high risk (b). PFS, progressionfree survival.

We then restricted our analysis to patients treated with adjuvant RAI, defined in intermediate-risk patients by tumour size $>4 \mathrm{~cm}$, microscopic ETE, central (N1a) and lateral (N1b) lymph node involvement, or post-operative $\mathrm{Tg}$ between 10 and $30 \mu \mathrm{g} / \mathrm{L}$; and high-risk patients without structural disease and $\mathrm{Tg}<30 \mu \mathrm{g} / \mathrm{L}$ (online suppl. Table 3 ). As shown in Figure 3, there was no significant difference between $\mathrm{H} 1$ and $\mathrm{H} 2$ activities categories for either intermediate-risk $(p=0.17)$ or high-risk patients $(p=0.15)$.

\section{Discussion}

In the current study, we demonstrate RAI activities significantly decreased at our institution over the last decade. Time points associated with the greatest decrease in RAI activities were 2010-2011 and 2016-2017, coinciding with release of 2009 and 2015 ATA guidelines, respectively. Unlike previous studies which have described translation of ATA guidelines into practice, our data also captures clinical and dosing information [21]. The greatest change in RAI selection over time was the use of lower activities for low-risk patients and a reduction in activities $>4 \mathrm{GBq}$ $(>108 \mathrm{mCi})$ for intermediate-risk patients. In the 11 year time period, our data demonstrate 14 times increase in the number of low-activity treatments administered. Despite using lower RAI activities, there has been no increased risk of recurrence over median follow-up period of 42 months (IQR 15.0-81.3 months), which is in keeping with long-term follow-up data for low-risk patients in recently published prospective trials and meta-analysis [7, 9, 22].
Our study did not examine outcomes of patients who did not receive RAI, however, our numbers show increased number of patients managed without RAI.

Despite adoption of lower activities of RAI, 36.4\% $(12 / 33)$ of patients classified as low-ATA risk in 20172018 received a high-RAI activities (online suppl. Table 4). Of those low-risk patients treated with a high activities, half had multifocal disease. Multifocal disease is not classified as an independent risk factor in the ATA guidelines, so it is interesting our quaternary centre was still influenced by this criterion in recent years.

There are many potential consequences of using lower RAI activities, including reduced side-effects, decreased hospital length of stay, and decreased overall costs [23]. At our institution, patients are admitted for 1 day for a 1 $\mathrm{GBq}(27 \mathrm{mCi})$ dose, 2 days for a $2 \mathrm{GBq}(54 \mathrm{mCi})$ dose, and 3 days for a $6 \mathrm{GBq}(162 \mathrm{mCi})$ activities. A $50 \%$ reduction was seen in the number of $6 \mathrm{GBq}(162 \mathrm{mCi})$ activities administered over the 11 years, resulting overall in $11 \%$ lower hospital bed usage (average length of stay decreasing from 2.14 to 1.9 days).

RAI activity selection is based on multiple clinical and histopathological factors. The 2015 ATA risk stratification proposes general dosing recommendations. However, these guidelines have not been endorsed by all major organizations involved in management of thyroid cancer [24]. We examined patient and disease factors influencing RAI activities selection including factors not currently incorporated in the ATA guidelines. Factors included in the 2015 ATA risk stratification were extra-thyroidal extension and venous invasion, and these were both as- 
sociated with the activity selected in recent years. Outside the ATA guidelines, other factors significantly associated with the activities selected in our series were age, gender, tumour size, and central, or lateral LN involvement. Our data, therefore, reflect the Martinique principles, which highlight important factors outside of post-operative status and risk stratification in activity choice [25]. The lack of uniformity in decision-making around RAI therapy results in patients receiving a wide range of RAI activities [26]. An intersocietal working group was formed in 2017 to foster collaboration in the management of patients with DTC and to progress a consensus approach [27].

There is an unequivocal benefit of using higher RAI activities in high-risk patients with known structural persistence/recurrence [28]. In contrast, the optimal activities for adjuvant RAI, to treat suspected but not confirmed residual disease, remains controversial [10,29-32]. Indeed, a definition for suspected residual disease has yet to be clearly defined [13]. The ATA guidelines currently recommend considering adjuvant RAI in intermediate-risk patients with higher risk features not currently incorporated in ATA risk stratification; in this respect, post-operative, stimulated $\mathrm{Tg}$ between 10 and $30 \mu \mathrm{g} / \mathrm{L}$ has been proposed as a marker for the use of adjuvant therapy [5]. In our analysis, using a strict definition of adjuvant therapy which combined higher risk features and raised post-operative $\mathrm{Tg}$, we could not identify a benefit of $\sim 6 \mathrm{GBq}(162 \mathrm{mCi}, \mathrm{H} 2)$ over $\sim 4 \mathrm{GBq}$ $(108 \mathrm{mCi}, \mathrm{H1})$ in either intermediate or high-risk patients. Our data questions whether higher activities are required in adjuvant treatment in either intermediate or high-risk patients, which could be addressed by future clinical trials.

Our study, unlike others, assessed clinically significant recurrence, defined as receiving a second RAI activities or further operative management. Our recurrence rates of 3.8, 3.7 , and $16.5 \%$ for low, intermediate, and high ATA risk groups, respectively, were similar to the structural incomplete response rates of another large study in this area [33].

The key strengths of our study are its size and long follow-up period of 11 years. Although our analyses were retrospective, all data were prospectively entered into our institutional database. Our study has several weakness: it is a single-centre study, our confidence in recurrence rates after lower RAI activities is tempered by temporal changes in RAI dosing, that is, patients treated with lower activities in later years have had shorter follow-up thereby limiting the capture of recurrence data; our use of Tg 10-30 $\mu \mathrm{g} / \mathrm{L}$ in the definition of adjuvant therapy for intermediate-risk patients may have missed some intermediate-risk patients with residual disease $[18,34]$; and we cannot exclude the possibility some recurrences may have been treated out- side our institution and, therefore, not captured in our database. We also cannot conclude our results, particularly in regard to low-recurrence rates, may be generalized to community care settings or other countries.

\section{Conclusion}

Our data demonstrates an evolution of RAI activity selection consistent with translation of ATA guidelines into local practice. Specifically, low-ATA risk patients now typically receive no $>2 \mathrm{GBq}(54 \mathrm{mCi})$ at our institution. The use of lower RAI activities in low-risk patients was not accompanied by any observable increase in recurrence risk. Our analysis could not show any benefit for $6 \mathrm{GBq}(162 \mathrm{mCi})$ over $4 \mathrm{GBq}(108 \mathrm{mCi})$, RAI in intermediate- or high-risk patients treated with adjuvant intent. A randomized control trial is warranted to clarify the optimal RAI activities in the adjuvant setting.

\section{Acknowledgements}

The authors acknowledge the technical assistance of (Alex Shaw) of the Sydney Informatics Hub, a Core Research Facility of the University of Sydney.

\section{Statement of Ethics}

All patients included in this study have given their informed written consent. This study was completed ethically in accordance with the World Medical Association Declaration of Helsinki and was approved by the Human Research Ethics Committee at Northern Sydney Local Health District (ETH00360/STE006443).

\section{Conflict of Interest Statement}

There is no conflict of interest that could be perceived as prejudicing the impartiality of the research reported. No author has competing financial interests.

\section{Funding Sources}

This project was funded in kind by all the authors.

\section{Author Contributions}

All the authors were responsible for writing, reviewing, and editing the manuscript.
Wijewardene et al. 


\section{References}

1 Deng Y, Li H, Wang M, Li N, Tian T, Wu Y, et al. Global burden of thyroid cancer from 1990 to 2017. JAMA Netw Open. 2020;3(6): e208759.

2 Australian Institute of Health and Welfare. Cancer Incidence Projections Australia 20112020 Cancer Series 66. Available from: http:// www.aihw.gov.au/WorkArea/DownloadAsset.aspx?id=10737421440. Accessed 2019 Jun.

3 Pandeya N, McLeod DS, Balasubramaniam K, Baade PD, Youl PH, Bain CJ, et al. Increasing thyroid cancer incidence in Queensland, Australia 1982-2008: true increase or overdiagnosis? Clin Endocrinol. 2016;84(2):257-64.

4 Sherman SI. Thyroid carcinoma. Lancet. 2003;361(9356):501-11.

5 Haugen BR, Alexander EK, Bible KC, Doherty GM, Mandel SJ, Nikiforov YE, et al. 2015 American thyroid association management guidelines for adult patients with thyroid nodules and differentiated thyroid cancer: the American Thyroid Association guidelines task force on thyroid nodules and differentiated thyroid cancer. Thyroid. 2016;26(1):1-133.

6 Schlumberger M, Catargi B, Borget I, Deandreis D, Zerdoud S, Bridji B, et al. Strategies of radioiodine ablation in patients with lowrisk thyroid cancer. N Engl J Med. 2012; 366(18):1663-73.

7 Schlumberger M, Leboulleux S, Catargi B, Deandreis D, Zerdoud S, Bardet S, et al. Outcome after ablation in patients with low-risk thyroid cancer (ESTIMABL1): 5-year followup results of a randomised, phase 3 , equivalence trial. Lancet Diabetes Endocrinol. 2018; 6(8):618-26.

8 Mallick U, Harmer C, Yap B, Wadsley J, Clarke S, Moss L, et al. Ablation with low-dose radioiodine and thyrotropin alfa in thyroid cancer. N Engl J Med. 2012;366(18):1674-85.

9 Dehbi HM, Mallick U, Wadsley J, Newbold K, Harmer C, Hackshaw A. Recurrence after low-dose radioiodine ablation and recombinant human thyroid-stimulating hormone for differentiated thyroid cancer (HiLo): long-term results of an open-label, non-inferiority randomised controlled trial. Lancet Diabetes Endocrinol. 2019;7(1):44-51.

10 Jonklaas J, Sarlis NJ, Litofsky D, Ain KB, Bigos ST, Brierley JD, et al. Outcomes of patients with differentiated thyroid carcinoma following initial therapy. Thyroid. 2006; 16(12):1229-42.

11 Carhill AA, Litofsky DR, Ross DS, Jonklaas J, Cooper DS, Brierley JD, et al. Long-term outcomes following therapy in differentiated thyroid carcinoma: NTCTCS registry analysis 1987-2012. J Clin Endocrinol Metab. 2015; 100(9):3270-9.

12 Rubino C, de Vathaire F, Dottorini ME, Hall P, Schvartz C, Couette JE, et al. Second primary malignancies in thyroid cancer patients. Br J Cancer. 2003;89(9):1638-44.

13 Tuttle RM. Distinguishing remnant ablation from adjuvant treatment in differentiated thyroid cancer. Lancet Diabetes Endocrinol. 2019;7(1):7-8.

14 Radowsky JS, Howard RS, Burch HB, Stojadinovic A. Impact of degree of extrathyroidal extension of disease on papillary thyroid cancer outcome. Thyroid. 2014;24(2):241-4.

15 Randolph GW, Duh QY, Heller KS, LiVolsi VA, Mandel SJ, Steward DL, et al. The prognostic significance of nodal metastases from papillary thyroid carcinoma can be stratified based on the size and number of metastatic lymph nodes, as well as the presence of extranodal extension. Thyroid. 2012;22(11):1144-52.

16 O'Neill CJ, Vaughan L, Learoyd DL, Sidhu SB, Delbridge LW, Sywak MS. Management of follicular thyroid carcinoma should be individualised based on degree of capsular and vascular invasion. Eur J Surg Oncol. 2011; 37(2):181-5.

17 Heemstra KA, Liu YY, Stokkel M, Kievit J, Corssmit E, Pereira AM, et al. Serum thyroglobulin concentrations predict disease-free remission and death in differentiated thyroid carcinoma. Clin Endocrinol. 2007;66(1):58-64.

18 Robenshtok E, Grewal RK, Fish S, Sabra M, Tuttle RM. A low postoperative nonstimulated serum thyroglobulin level does not exclude the presence of radioactive iodine avid metastatic foci in intermediate-risk differentiated thyroid cancer patients. Thyroid. 2013;23(4): $436-42$.

19 Ito Y, Kudo T, Kihara M, Takamura Y, Kobayashi K, Miya A, et al. Prognosis of low-risk papillary thyroid carcinoma patients: its relationship with the size of primary tumors. Endocr J. 2012;59(2):119-25.

20 Ryerson Index [updated 2020 Oct 15]. Available from: http://ryersonindex.org/search. php.

21 Jacobs D, Breen CT, Pucar D, Holt E, Judson BL, Mehra S. Changes in population-level and institutional-level prescribing habits of radioiodine therapy for papillary thyroid cancer. Thyroid. 2021 Feb;31(2):272-9.

22 Vardarli I, Weidemann F, Aboukoura M, Herrmann K, Binse I, Görges R. Longer-term recurrence rate after low versus high dose radioiodine ablation for differentiated thyroid cancer in low and intermediate risk patients: a meta-analysis. BMC Cancer. 2020;20(1): 550.

23 Al-Qurayshi Z, Bu Ali D, Srivastav S, Kandil E. Financial implication of radioactive iodine therapy for early-stage papillary thyroid cancer. Oncology. 2017;93(2):122-6.

24 Verburg FA, Aktolun C, Chiti A, Frangos S, Giovanella L, Hoffmann M, et al. Why the European Association of nuclear medicine has declined to endorse the 2015 American Thyroid Association management guidelines for adult patients with thyroid nodules and differentiated thyroid cancer. Eur J Nucl Med Mol Imaging. 2016;43(6):1001-5.

25 Tuttle RM, Ahuja S, Avram AM, Bernet VJ, Bourguet P, Daniels GH, et al. Controversies,
Consensus, and Collaboration in the Use of (131)I therapy in differentiated thyroid cancer: a joint statement from the American Thyroid Association, the European Association of nuclear medicine, the society of nuclear medicine and molecular imaging, and the European Thyroid Association. Thyroid. 2019; 29(4):461-70.

26 Sawka AM, Goldstein DP, Thabane L, Brierley JD, Tsang RW, Rotstein L, et al. Basis for physician recommendations for adjuvant radioiodine therapy in early-stage thyroid carcinoma: principal findings of the CanadianAmerican thyroid cancer survey. Endocr Pract. 2008;14(2):175-84.

27 Verburg FA, Ahuja S, Avram AM, Bardiès M, Bernet $\mathrm{V}$, Bourguet $\mathrm{P}$, et al. Brief progress report from the intersocietal working group on differentiated thyroid cancer. Eur J Nucl Med Mol Imaging. 2020;47(6):1345-7.

28 Gray KD, Bannani S, Caillard C, Amanat S, Ullmann TM, Romanov P, et al. High-dose radioactive iodine therapy is associated with decreased risk of recurrence in high-risk papillary thyroid cancer. Surgery. 2019;165(1): $37-43$.

29 Ruel E, Thomas S, Dinan M, Perkins JM, Roman SA, Sosa JA. Adjuvant radioactive iodine therapy is associated with improved survival for patients with intermediate-risk papillary thyroid cancer. J Clin Endocrinol Metab. 2015;100(4):1529-36.

30 Castagna MG, Cevenini G, Theodoropoulou A, Maino F, Memmo S, Claudia C, et al. Postsurgical thyroid ablation with low or high radioiodine activities results in similar outcomes in intermediate risk differentiated thyroid cancer patients. Eur J Endocrinol. 2013; 169(1):23-9.

31 Sabra MM, Grewal RK, Ghossein RA, Tuttle RM. Higher administered activities of radioactive iodine are associated with less structural persistent response in older, but not younger, papillary thyroid cancer patients with lateral neck lymph node metastases. Thyroid. 2014;24(7):1088-95.

32 Han JM, Kim WG, Kim TY, Jeon MJ, Ryu JS, Song DE, et al. Effects of low-dose and highdose postoperative radioiodine therapy on the clinical outcome in patients with small differentiated thyroid cancer having microscopic extrathyroidal extension. Thyroid. 2014;24(5):820-5.

33 Grani G, Zatelli MC, Alfò M, Montesano T, Torlontano M, Morelli S, et al. Real-world performance of the American thyroid association risk estimates in predicting 1-year differentiated thyroid cancer outcomes: a prospective multicenter study of 2000 patients. Thyroid. $2021 \mathrm{Feb}$;31(2):264-71.

34 de Rosário PW, Guimarães VC, Maia FF, Fagundes TA, Purisch S, Padrao EL, et al. Thyroglobulin before ablation and correlation with posttreatment scanning. Laryngoscope. 2005;115(2):264-7. 